\title{
Plant Evaluation Program for Nursery Crops and Landscape Systems by the Southern Extension and Research Activities/Information Exchange Group-27
}

\author{
W.C. Dunwell, ${ }^{1}$ D. Fare, ${ }^{2}$ M.A. Arnold ${ }^{3}$ K. Tilt,${ }^{4}$ G. Knox,${ }^{5}$ W. Witte, ${ }^{6}$ P. Knight,${ }^{7}$ M. Pooler,${ }^{8}$ \\ W. Klingeman, ${ }^{9}$ A. Niemiera, ${ }^{10}$ J. Ruter, ${ }^{11}$ T. Yeager ${ }^{12}$ T. Ranney, ${ }^{13}$ R. Beeson,${ }^{14}$ J. Lindstrom, ${ }^{15}$ \\ E. Bush, ${ }^{16}$ A. Owings, ${ }^{17}$ and M. Schnelle ${ }^{18}$
}

Additional INDEX words. plant evaluation, landscape plants, plant materials, landscape management, plant culture

Summary. The Southern Extension and Research Activities/Information Exchange Group-27 (SERA/IEG-27) is sponsored by the Southern Association of Agricultural Experiment Station Directors. Thirteen universities and the U.S. National Arboretum cooperate with official representatives from extension and research programs. The objective of the group is to identify, evaluate, select, and disseminate information on superior, environmentally sustainable, landscape plants for nursery crop production and landscape systems in the southeastern U.S. Plants are distributed to members responding to a request from cooperators for plant evaluation. Those who agree to cooperate are expected to grow the selected liner to landscape size, then transplant it in a landscape setting. The plant is rated for insect, disease, and cold damage, heat stress, growth rate, ornamental flowering and fruiting, fall color, commercial production potential, landscape potential, invasiveness potential, and insect disease transmission potential. Growth rate is evaluated annually by recording plant height and width. Initial bloom date is reported followed by bloom duration in days. Following evaluation, the group collectively and individually disseminates information gained from the plant evaluation system to a wide variety of audiences.
The Southern Regional Extension and Research Activity/Infor- mation Exchange Group-27 was established in 1994 and is 1 composed of research and extension horticulture faculty from southern land- grant universities and the U.S. National Arboretum with a common interest in land- scape plant evaluation.

The cost of publishing this paper was defrayed in part by payment of page charges. Under postal regulations, this paper therefore must be hereby marked advertisement solely to indicate this fact.

${ }^{1}$ University of Kentucky Research and Education Center, P.O. Box 469, Princeton, KY 42445

${ }^{2}$ USDA, ARS, Floral and Nursery Plants Research Unit, 472 Cadillac Lane, McMinnville, TN 37110.

${ }^{3}$ Texas A\&M University, Department of Horticulture Sciences, College Station, TX 778743.

${ }^{4}$ Auburn University, Department of Horticulture, 101 Funchess Hall, Auburn, AL 36849.

${ }^{5}$ Uinversity of Florida, North Florida Research and Education Center, 30 Research Road, Quincy, FL 32351.

${ }^{6}$ University of Tennessee, Department of Ornamental Horticulture and Landscape Design, P.O. Box 1071, Knoxville, TN 37901.

${ }^{7}$ Mississippi State University, South Mississippi Branch Experiment Station, P.O. Box 193, Poplarville, MS 39470.

${ }^{8}$ U.S. National Arboretum, 3501 New York Avenue NE, Washington, DC 20002.

${ }^{9}$ University of Tennessee, Department of Ornamental Horticulture and Landscape Design, 252 Ellington Plant Science Building, Knoxville, TN 37996.

${ }^{10}$ Virginia Polytechnic Institute and State University, Department of Horticulture, Blacksburg, VA 24061.

${ }^{11}$ University of Georgia, Department of Horticulture, Coastal Plain Station, Tifton, GA 31793.

${ }^{12}$ University of Florida, Environmental Horticulture Department, 1445 Fifield Hall, Gainesville, FL 32611.

${ }^{13}$ North Carolina State University, Mountain Horticultural Crops Research and Extension Center, 2016 Fanning Bridge Road, NC 28732.

${ }^{14}$ University of Florida, Mid-Florida Research and Education Center, 2725 Binion Road, Apopka, FL 32703.

${ }^{15}$ University of Arkansas, Horticulture Department, Plant Science Building 316, Fayettevillle, AR 72701.

${ }^{16}$ Louisiana State University, Department of Horticulture, 137 J. C. Miller Hall, Baton Rouge, LA 70803.

${ }^{17}$ Louisiana Cooperative Extension Service, P.O. Box 25100, Louisiana State University, Baton Rouge, LA 70894.

${ }^{18}$ Oklahoma State University, Horticulture and Landscape Architecture Department, 360 AG Hall, Stillwater, OK 74076. 
SERA/IEG-27 is sponsored by the Southern Association of Agricultural Experiment Station Directors. The purpose of SERA/IEG-27 is to bring together, often on an annual basis, researchers and specialists to exchange current information on the status of new research findings, to gain regional perspective on current problems and to consider possible joint activities (Raspberry and Helms, 2001).

Continued growth of the nursery/ landscape industries is invigorated by the introduction of new plants that have performed well in diverse landscape and environmental conditions. Individual nurseries, plant associations, universities, and other state and federal agencies actively seek, evaluate and introduce plants to the industry. Often plants are introduced that have only been evaluated in a few microenvironments, although the plants will be distributed, marketed, and planted throughout a much wider region. To remain credible, the industry needs unbiased evaluations of plant materials that are conducted in a range of different environments. The results of plant evaluations should be shared with a wide audience. SERA/ IEG-27 has provided a mechanism for university faculty with independent plant evaluation programs to coordinate unbiased, regional evaluation of new or underused plants.

SERA/IEG-27 is composed of official research and extension representatives from the University of $\mathrm{Ar}$ kansas, Auburn University, Clemson University, University of Florida, University of Georgia, University of Kentucky, Louisiana State University, Mississippi State University, North Carolina State University, Oklahoma State University, University of Tennessee, Texas A\&M Univ., Virginia Tech, and the U.S. National Arboretum.

\section{Objectives}

The objectives of SERA/IEG-27 are to 1 ) identify, evaluate, select, and disseminate information on superior environmentally sustainable landscape plants for nursery crop production and landscape systems in the southeastern U.S. and 2) collectively and individually disseminate information gained from the plant evaluation system such as cold hardiness, heat tolerance, growth rate, environmental adaptation limits, invasiveness, and aesthetic value to a wide variety of audiences.

\section{Plant distribution}

Protocols have been developed to efficiently distribute and evaluate plants. A member introduces a plant for evaluation and representatives from each state vote on inclusion of the plant in the evaluation process. Each representative has the option of including the approved plant in his/her evaluation plots. The member then distributes the plant at an optimum time for planting and establishing in landscape demonstration and research plots. Plants are sent to evaluators with a distribution form that provides the following information: an entry number (year-state-taxon); replication number; botanic and common name of the plant; distributor name, address, telephone number, and e-mail address; time, place, and method of propagation; recommended cultural practices; recommended planting location; projected size of the mature plant; projected hardiness zone; projected number of years required for evaluation and a recommended plant standard to be used for comparison (if any). Other specific evaluation data required but not listed on the evalua-

Table 1. Plants evaluated by Southern Extension and Research Activities/Information Exchange Group-27 representatives.

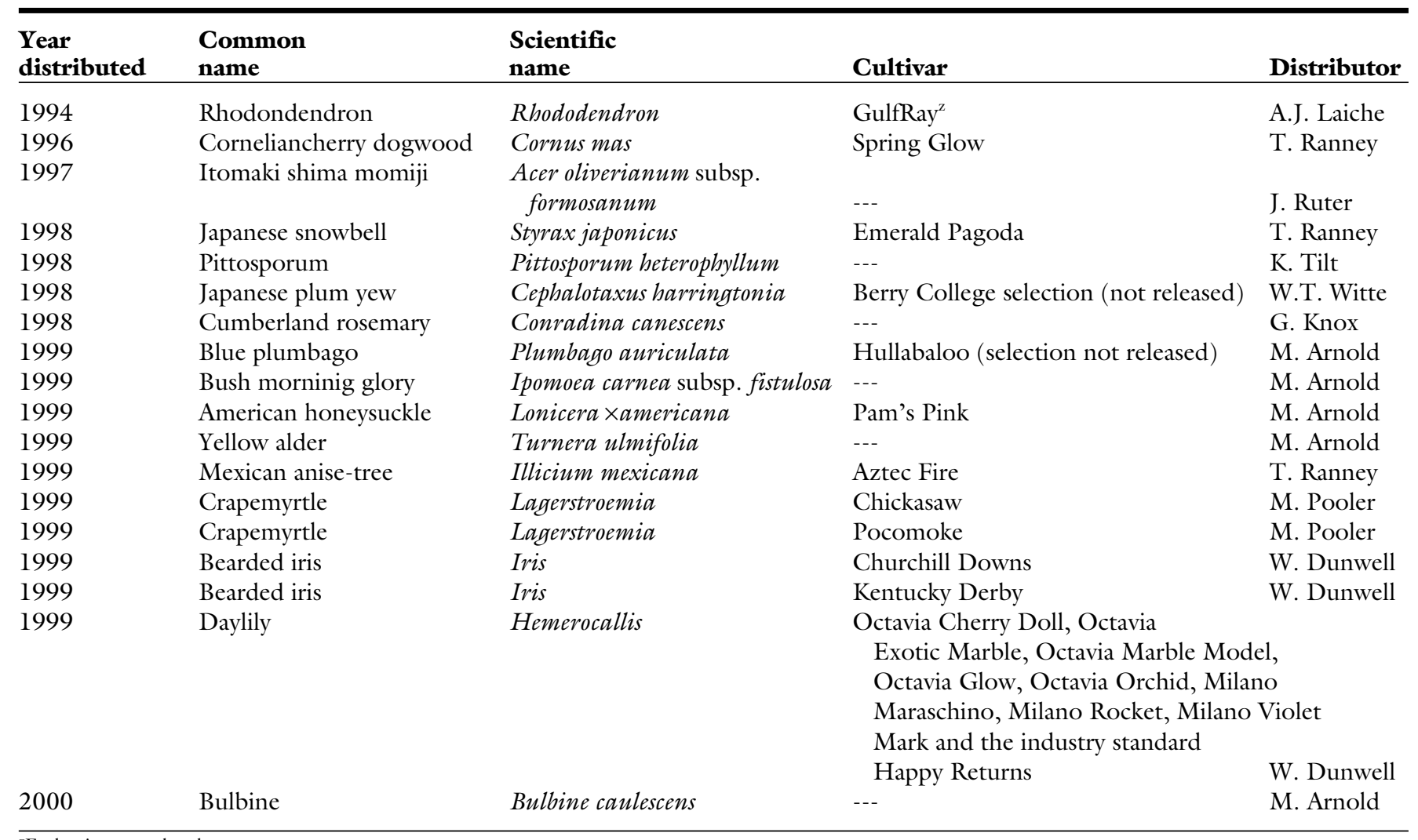

${ }^{\mathrm{z}}$ Evaluation completed. 
tion form may include: the date of distribution and the name of the evaluators. Digital images of the plant posted to the SERA/IEG-27 web site are included with a distribution form sent to the SERA/IEG-27 web master.

\section{Plant establishment}

Plants are distributed as liners that are container grown by the evaluator to a size that can be planted in a trial garden or landscape. Production practices are the standard for the evaluator unless specific recommendations are made by the distributor.

\section{Plant evaluation}

Evaluation data are entered by the individual members on the SERA/ IEG-27 web site (Tilt and Fischman, 2001 ) maintained by Auburn University. The password-protected evaluation form asks for the following information: evaluator identification number; replication number; year of evaluation; plant entry number; plant name; distributor name; evaluator name; evaluation location; evaluation zone; exposure (sun or shade); irrigation (yes or no); date (month/day/year) received for evaluation; date planted to field; and the date of evaluation. Evaluation data are numerical in the form of a measurement or a rating from 1-10. Plant height (centimeters) and plant width (centimeters) are measured. For evaluation of insect, disease, cold, and heat damage, the range is $1=$ no damage to $10=$ severely damaged. Growth, flower, fruit, fall color, production, landscape, insect disease transmission, and invasiveness potentials are evaluated on a scale of $1=$ no value/potential to $10=$ great value / potential. Initial bloom date is in month/day/year and bloom duration is reported as number of days. Additional evaluation data can be requested by the distributor.

A compilation of the data by the plant evaluation committee is made available for members to use in their educational programs. Evaluation results are presented on the SERA-IEG27 web site (Tilt and Fischman, 2001). Plants currently in the formal evaluation process are listed below in order of the year they were included in the evaluation and the originating distributor (Table 1).

\section{Literature cited}

Rasberry, A.M. and T.J. Helms. 2001. Southern Association of Agricultural Experiment Station Directors; Southern Extension/Research Activities (SERAs). 2 May 2001. <http://www.msstate.edu/ org/saaesd/infobook/project/sera.htm>.

Tilt, K. and B. Fischman. 2001. SERA/ IEG-27; Southern Extension Research Activity; Information Exchange Group. 2 May 2001. <http://www.ag.auburn.edu/ landscape/SERAhomepage.html> 